\title{
FREE GRAFT REPAIR IN PILONIDAL SINUS
}

By D. Wynn Williams, M.S.(Lond.), F.R.C.S.

Plastic Surgery and Faw Injuries Centre, Queen Victoria Hospital, East Grinstead, Sussex

The problem of satisfactory treatment of the pilonidal sinus is so well-known as to require no further justification for reporting a method of repair only briefly mentioned in the literature.

The aetiology and pathology of pilonidal sinus has been fully discussed in many papers and though varied theories have been propounded it will suffice to mention only a few. The most widely accepted theory is that of Sir John Bland Sutton (1917) who suggested that a congenital faulty skin coalescence in the middle line of the lower sacral region of the back may lead to the formation of post anal dimples and coccygeal sinuses, and these may be termed sequestration dermoids. Patey and Scarff (1946) suggest that only a small proportion of sinuses are developmental in origin and that the majority are primarily of an infective origin. King (1947) believes that irritation in the intergluteal folds leads to a depression or crypt and this crypt becomes the repository of debris and hairs, ultimately infection with sinus formation occurs. Davies and Starr (1945) quote and confirm Kooistra's (1942) findings of multiple midline dimples in the caudal midline zone of embryos and their persistence through adult life, they draw attention to the fact that the skin of the natal cleft is thin and contrasts with the thicker texture of the skin of the buttock proper, and in many individuals the natal cleft manifests one or more dimples which they believe to be embryonic relics and potential pilonidal sinuses. They give a detailed anatomical description of the fascia binding the skin of the natal cleft to the sacrum and coccyx and postulate reasons for the sinuses being more commonly found extending upwards and to the left of the midline. They point out that the blood supply to the natal cleft in the midline is by means of small branches from the posterior perforating arteries which emerge from the sacral foramina and a strictly midline blood supply does not exist.

The treatment of the acutely inflamed pilonidal sinus is well understood but the problem lies in the handling of the non-inflamed and recurrent sinuses. The sinus must be excised together with all epithelial lined tracts and it is preferable that surgery should be undertaken when the sinus is in a quiescent phase, with little discharge ande no signs of acute inflammation in the surrounding. tissues. The amount of skin excised may be variable but must include all the sinus openings. $\omega$ The tissues defect will therefore be great in all butơ the simplest, non-infected cases, and the probleme of repair of this tissue defect is one that has taxed the ingenuity of many surgeons and is undoubtedlyo a major cause in the very high 'recurrence' rate.

Primary closure with direct approximation of the wound edges is the quickest and most satis $-\frac{0}{\omega}$ factory treatment.

Davies and Starr state that this method $\Phi \overrightarrow{f e}$ repair is possible if:

I. It is realised that the subcutaneous wourdic is larger than the skin defect, so that overhanging? skin edges are the rule, and the obliteration of the subcutaneous defect is as important as sking closure because the nutrition at the wound edgeso is impaired when its subcutaneous supports have $\Rightarrow$ been removed.

2. It is recognized that the blood supply of the midline natal cleft is poor when compared to that of the buttock.

3. The rigidity of the buttock is appreciated The dense fascia of the buttock and its fixation byo the natal cleft fascia militate against the use of buttock fat to close the subcutaneous dead space.

4. It is appreciated that tension of a degree which would be permissible in wounds in othero sites is excessive in the natal cleft.

5. A haematoma developing under the suture line can be disastrous.

Unfortunately in many patients direct closure is unsuccessful and for this reason a large number of alternative surgical procedures have beent described; they include:

I. Excision and healing by granulation; thiso is time-consuming and in many instances painful procedure.

2. Sliding flaps of gluteus maximus as describedo by Pope and Hudson (1946).

3. Estlander flaps, which are designed to rotaten 


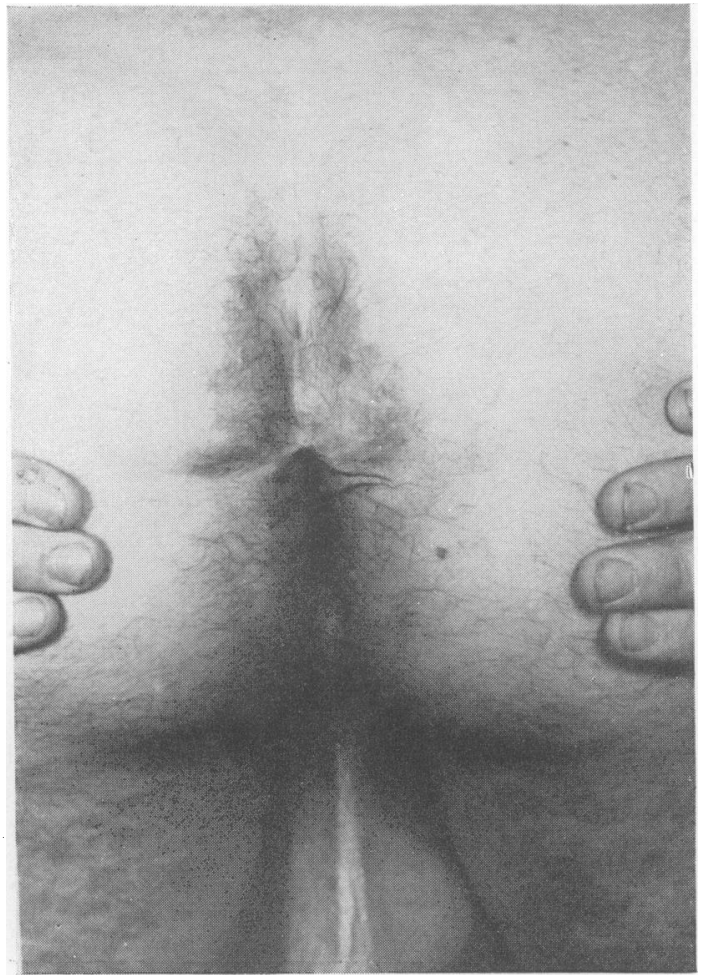

FIG. 1.-Case I. Natal cleft with scarring and opening of sinus.

into the defect as described by Davies and Starr. These are satisfactory in most cases, but it involves a lengthly operation and in some cases a marginal skin loss occurs. The healing time is then protracted; haematoma formation beneath such flaps is utterly disastrous.

4. Dissection of the sinus from under a full thickness flap of the local skin which is then resutured over the defect, Brezin (1943).

5. The simpler procedure and far less time consuming method described by Boger and Pinkham (195 r) of using a split skin graft to cover the defect.

The following two cases of recurrent pilonidal sinuses are described in detail:

\section{Case I}

J.C.S.-male aged 30 years. Occupation: Seaman in the Royal Navy. In February 195I, while serving at sea, he developed a pilonidal abscess, which was treated by local applications and allowed to discharge spontaneously, and the purulent discharge persisted for four weeks.

Six months later he was admitted to a hospital where complete excision of the sinus, and epithelial lined tract was carried out. The wound was left open and packed, and healing by granulation took

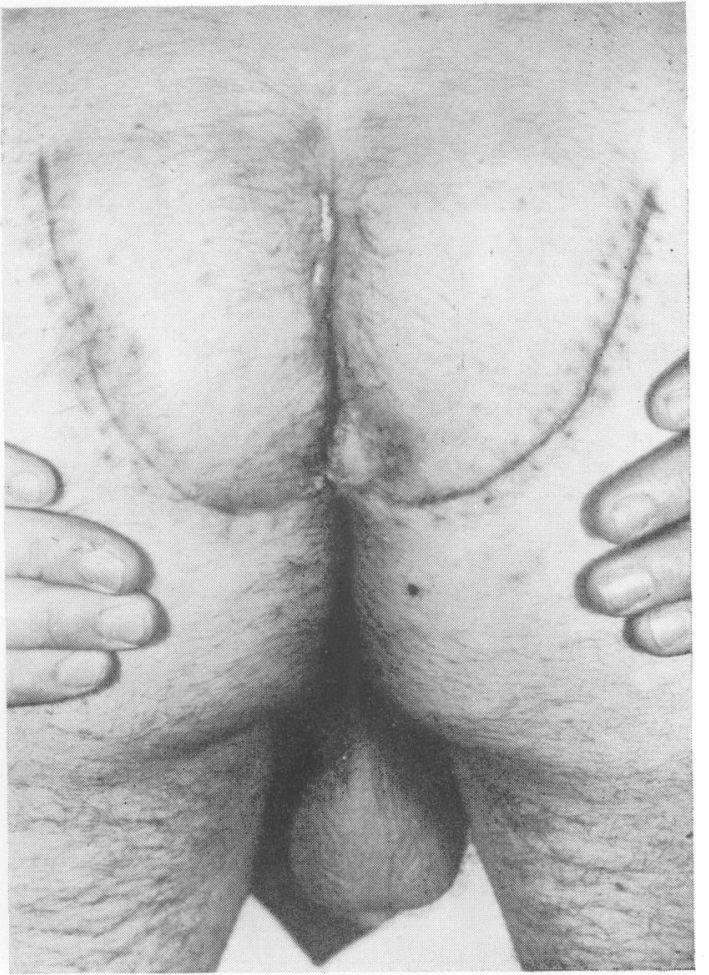

FIG. 2.-Case I. Rotation flaps in position.

place. Subsequently, two further operations using the same technique were performed. He was transferred to this Unit in July, 1952.

Examination. Normal heavily built man. C.V.S. C.N.S. R.S.-normal. B.P. $120 / 80$. Urine-normal.

Perineum. A large sinus was situated in the natal cleft, $I \frac{1}{2}$ in. in length and $2 \frac{1}{2}$ in. in depth, and the tract was lined with unhealthy granulation tissue. The surrounding skin was heavily scarred. (Fig. I).

Proctoscopy. The anal canal was normal.

Operation. The sinus, surrounding scarred skin, the tract and all palpable scar tissue was excised. Double rotation flaps were then cut from the buttocks and sutured together in the midline to close the defect (Fig. 2).

Superficial loss of the edges of the rotational flaps occurred (Fig. 3 ) but the suture lines healed in four weeks. The patient remained free from recurrence for three months, but was readmitted at the end of that time because he had a discharge from the lower end of the central scar in the natal cleft. Exploration of the sinus showed a large abscess cavity situated beneath the right rotation flap. The abscess was evacuated and the pyogenic 


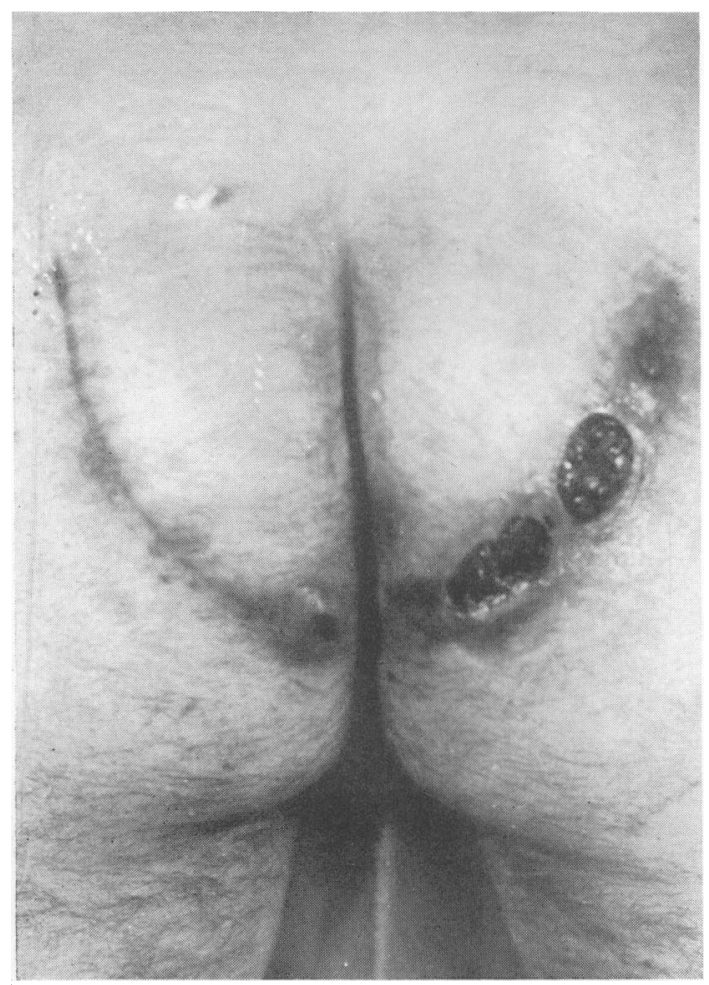

Fig. 3.-Case I. Superficial breakdown of suture lines of rotation flaps.

membrane removed, and the flaps were resutured. Subsequently, the patient complained of an intermittent purulent discharge from the midline scar. Six months later a further exploration of the sinus was carried out and the pyogenic membrane was stripped from a further abscess cavity. A stent mould was made of the defect and painted with mastasol, and a free graft cut from the thigh was wrapped on the mould raw surface outwards, and placed into the defect. The mould was secured in position and left undisturbed for six days. During the first four post-operative days the bowels were constipated by oral tinct. opii. Healing was complete in ten days, and at the end of six months there was no sign of recurrence (Fig. 4).

\section{Case 2}

G.H.M.-male, aged 35 years. Occupation: Officer in the Royal Navy. At the age of 33 years he developed an abscess in a pilonidal sinus. Immediate excision of the sinus and surrounding skin was carried out and direct primary suture of the subcutaneous fat and skin edges was performed. One month later a recurrence of the discharge was noticed. The sinus was re-excised, saucerized

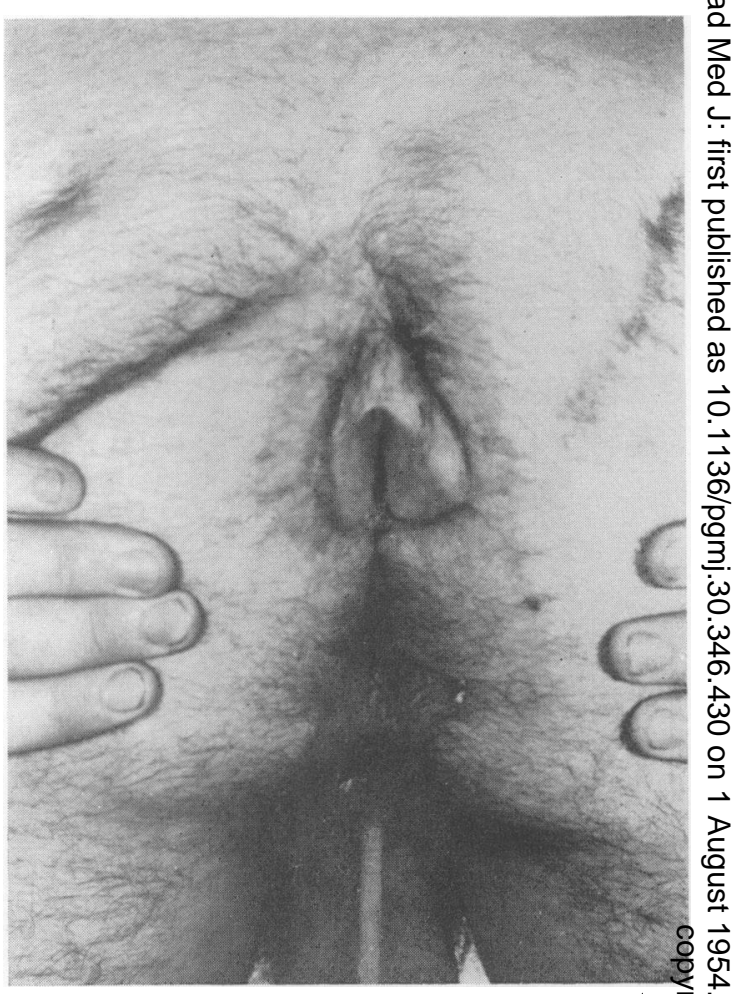

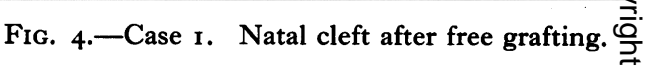

and the wound was packed and allowed to granu late. Four months later complete epithelialization had not occurred and he was referred to this Unit $\overrightarrow{\overrightarrow{0}}$ Examination. Normal healthy man. C.V.S C.N.S. R.S. - normal. B.P. 125/80. Urine- $\frac{?}{0}$
normal.

Perineum. There was a large unhealed areâ present in the natal cleft measuring 2 in. by 2 in? (Fig. 5).

Operation. Complete excision of the unhealed. area and surrounding skin edges was carried outo and mobilization and advancement of the gluteus maximus on both sides of the cleft allowed direc? suture of the muscle in the midline. The sub $\rightarrow$ cutaneous tissue and skin were then sutured undes. 'moderate' tension with nylon mattress suturesî

A small area of breakdown of the skin edges occurred in the middle of the suture line, and although epithelialization occurred the suture lines remained unstable. Four months later the patien⿷匚 was readmitted with a recurrence of the discharge and a sinus.

Excision of the sinus and surrounding skir ${ }^{+}$ together with all palpable scar tissue in the sub $\stackrel{0}{\bar{T}}$ cutaneous fat was performed. A Thiersch grafof was cut from the thigh, and was sutured into the 


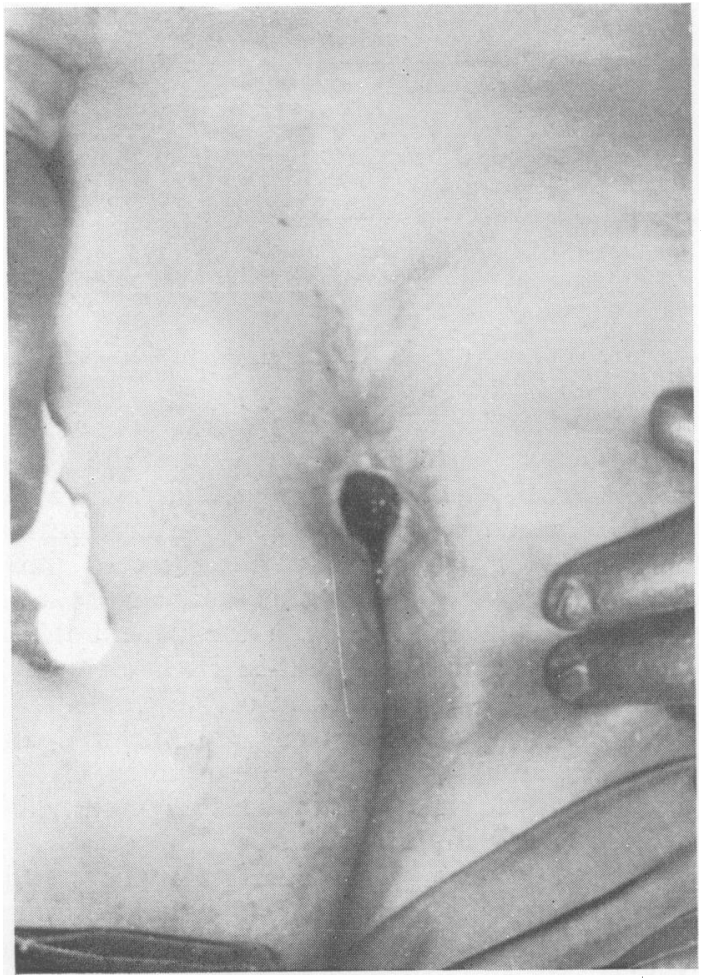

Fig. 5.-Case 2. Natal cleft showing unhealed area.

defect. The cavity was then carefully packed with flavine wool, even pressure being obtained by black silk oversutures. The graft took well and the cavity was healed in ten days. Eight months later there was no evidence of recurrence (Fig. 6).

\section{Discussion}

In considering the aetiology and pathology little can be added, except to draw attention to the possibility that those patients who present with multiple recurrences, and have multiple sinuses opening in the natal fold close to the anus, present a similar clinical picture to suppurative hidradenitis, in this condition no surgery falling short of excision 'en bloc' of all involved areas and subsequent skin graft, can be successful.

In assessing the value of split skin grafting of the defect after excision of a pilonidal sinus no suggestion is made that all cases should be treated in this way. In the small non-infected cysts where minimum excision is adequate, direct closure is the method of choice.

It is in those cases which have undergone repeated inflammatory attacks of the cyst and developed multiple sinus openings, or recurrence has occurred after excision and direct closure, that

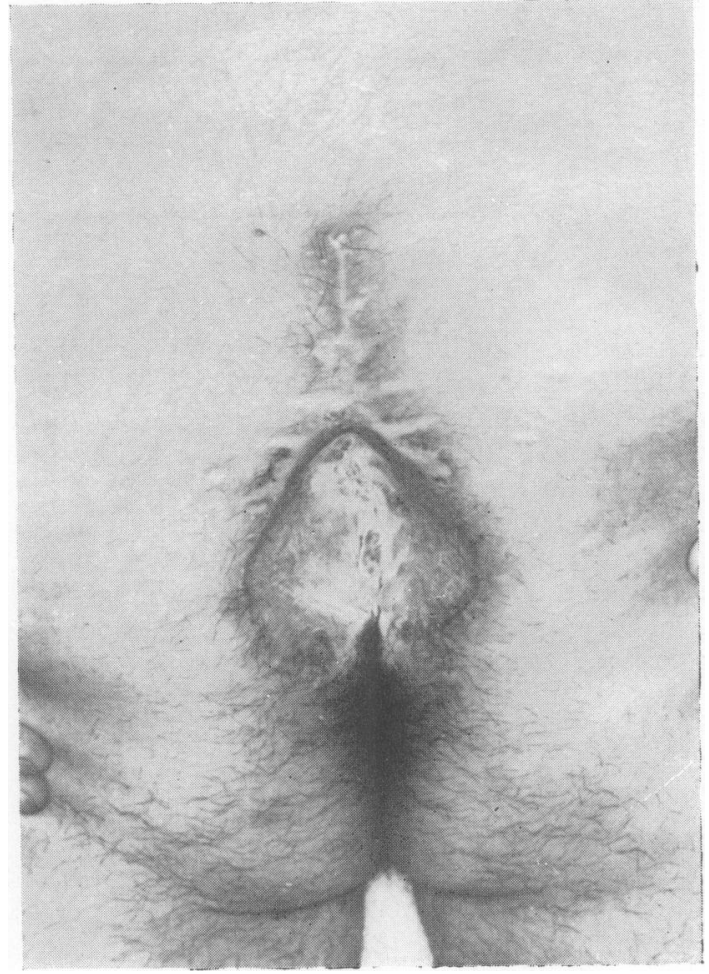

Fig. 6.-Case 2. Natal cleft after free grafting.

repair by a split skin graft is recommended. It allows a wide and adequate excision down to presacral fascia and provides a simple method of healing the tissue defect with the result that the time spent in hospital is lessened-a factor not to be forgotten in the age group in which this condition occurs. With adequate control of the bowels contamination of the graft is eliminated. Chemotherapy may be a useful adjunct, though in the two cases discussed, it was not given.

A further factor of note is that after one primary excision skin shortage plays a part in the recurrence and by a free graft this defect can be corrected. Tenting of the skin over a subcutaneous cavity is eliminated and the possibility of haematoma formation, almost certainly a factor in recurrence of this condition, is reduced.

Finally, the grafted skin rapidly settles in the natal fold and becomes adherent to the presacral fascial thereby approximating to the normal natal fold skin.

I am most grateful to Mr. F. T. Moore for his constant help and advice, and to Mr. G. Clemetson for the photographs.

Bibliography continued on next page 
A new Operation Table forms part of the exhibit of Allen \& Hanburys Ltd., at the Medical Exhibition held in conjunction with the Annual Conference of the British Medical Association in Glasgow from July 5 to 9 , 1954 .

Since the latter half of the last century, Allen \& Hanburys Ltd. have been producing Operation Tables and it is interesting to study the changes in design they have made to keep pace with modern surgical practice.

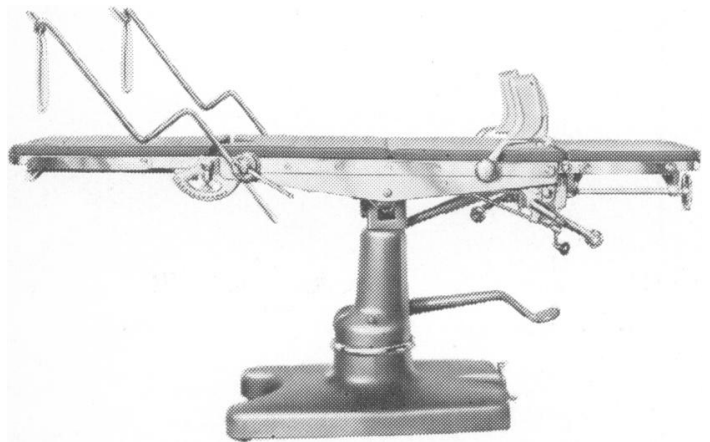

The Model ' $\mathrm{J}$ ' Operation Table is a completely new and advanced design in which all major adjustments are controlled from the head-end of the Table. This enables any adjustment of position of the Table to be made without interruption of the surgical team. The adoption of head-end control has been achieved without any sacrifice of rigidity, the Table being completely rigid in any of its extremely versatile range of positions and ensures ideal operation conditions. The following are details of its range of movement :

Minimum height, 29 in.

Maximum height, 43 in.

Maximum Trendelenburg, $45^{\circ}$.

Reverse Trendelenburg, $30^{\circ}$.

Lateral Tilt, Left and Right, $20^{\circ}$.
The table top is cast in corrosion-resistant aluminium alloy with a satin finish. The head flap is extendable and allows for fine angularadjustments and instant removal from the Table. $\vec{\rho}$

The leg flap also is fully adjustable and can bes removed instantly from the Table in any position? A carefully proportioned perineal recess allow. maximal exposure of the perineum for all diagnostic and surgical procedures with the patient in the lithotomy position. A built-in back elevator is controlled from the head-end of the Table.

All main gear mechanisms are enclosed ando particular attention has been given to the overall design so as to make routine cleaning and main- $\rightarrow$ tenance simple in the extreme.

For many years past, Allen \& Hanburys Ltd. have achieved a large measure of export business in Operation Tables and it is considered that thise Table, which combines unrivalled engineering craftsmanship with undisputed leadership design, will maintain their leading position in the export field.

Menley \& James, Limited, PharmaceuticaE Manufacturers, Coldharbour Lane, London, S.E. 5 ? announce a new addition to their 'Eskacillin $\frac{5}{0}$ range of palatable liquid oral penicillins-' Eska cillin' 200. This new high strength presents 200,000 I.U. procaine penicillin per standard medical teaspoonful (I fl. drachm: $3.5 \mathrm{ml}$.) ᄋ 'Eskacillin' 200 is indicated for the treatment of penicillin-sensitive infections. The dosage for children up to eight years is one teaspoonful three or four times a day, and for older children ande. adults two to three teaspoonfuls three or fout times a day. 'Eskacillin ' 200 is available, on pre scription only, in $2 \mathrm{fl}$. oz. ( $56 \mathrm{ml}$.) bottles.

Continued from previous page-D. WyNN WiLLIAMs, M.S.(LoND.), F.R.C.S.

\section{BIBLIOGRAPHY}

BLAND-SUTTON, SIR JOHN (I9I7), 'Tumours Innocent and Malignant,' 6th edition, p. 526 , Cassell and Co.

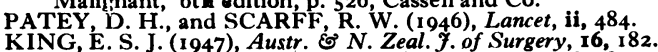

DAVIES, L. S., and STARR, K. W. (1945), S.G. E' O., 81, 309.
KOOISTRA, H. P. (1942), Am. F. Surg., 45, 3.

POPE, C. E., and HUDSON, H. W. (1946), Arch. of Surg., 52, 690 BREZIN, C. (1943), Am. Y. Surg., 59, 18.

BOGER, E. V., and PINKHAM, E, W. (1951), U.S. Armed Forces? med. 7., 2, 1733 . 